\title{
Strategic Analysis of WMD Nonproliferation: Iraq and After Iraq
}

\author{
Kaoru Ishiguro \\ Kobe University, Kobe, Japan
}

\begin{abstract}
We examine two strategies for the nonproliferation of weapons of mass destruction (WMD): "sanctions" and "monitoring and inspections". Our main conclusions are summarized as follows. Firstly, there is a substitutive relationship between sanctions and monitoring and inspections. We posit that the proliferation of WMD may be prevented through intensified sanctions or increased monitoring and inspections. Secondly, monitoring activities may be decreased through the increased effectiveness of sanctions aimed at preventing proliferation. Thirdly, if the increased development costs of WMD can decrease the need for inspection activities sufficiently, the extent of monitoring activities could also reduce.
\end{abstract}

Keywords: weapons of mass destruction (WMD), sanction, monitoring, inspection, Iraq

\section{Introduction}

In March 2003, just before the Iraq War, France, Germany, and Russia were opposed to the US and the UK over their handling of the Iraq situation. On the one hand, the US and the UK asserted the need for military sanctions (referred to as the first strategy in this paper) or armed action on the basis of Security Council Resolution 1441. On the other hand, France, Germany, and Russia urged the continuation of UN inspections (called the second strategy in this paper) in line with Resolution 1284. There was disagreement between both sides on whether they should destroy Iraqi weapons of mass destruction (WMD) via military sanctions or UN inspections.

The US, in particular, asserted the need for armed action on Iraq according to Resolution 1441. It argued that Iraq was seriously violating Resolution 1441 based on two lines of argument. Firstly, the Iraqi declaration of December 8, 2002 had been "inaccurate and incomplete". Secondly, Iraq had failed to provide the immediate, unconditional, and active cooperation that was required by the resolution to UN inspectors. Therefore, Iraq faced serious consequences according to Resolution 1441. The US noted that as per Article 51 of the UN Charter for self-defense, the presence of WMD allowed preemptive actions for self-defense without requiring any endorsement by the Council (Blix, 2004, p. 137, p.148).

In opposition to the US, France, Germany, and Russia asserted that according to Resolution 1284, the UN had to continue the inspections in Iraq. They urged the UN to set up some benchmarks for Iraq to disarm WMD, demanded that Iraq attained them, and were in favor of continuing inspections. As for armed action, they argued that UN inspectors would need to file a report on non-compliance by Iraq before any serious action could be considered, and that the use of armed forces required a Council decision (Blix 2004, p. 149). They

Kaoru Ishiguro, Professor, Graduate School of Economics, Kobe University. 
insisted on the disarmament of WMD through UN inspections, while the US and UK urged the UN to use military sanctions.

The purpose of this study is to examine two strategies of nonproliferation of WMD: "sanctions" and "monitoring and inspections". In particular, we consider the effects of sanctions on monitoring and inspections. WMD include nuclear weapons, biological weapons, and chemical weapons. The international community is subject to the following treaties: the Treaty on the Non-proliferation of Nuclear Weapons (NPT, opened for signature in 1968), the Biological Weapons Convention (BWC, signed in 1972), and the Chemical Weapons Convention (CWC, signed in 1993). These treaties intend to enforce WMD disarmament with the use of monitoring and inspection, and use admonitions and sanctions in the event of non-compliance. However, there is no system of inspection and verification of biological weapons ${ }^{1}$.

Our main conclusions are summarized as follows. Firstly, there is a substitutive relationship between sanctions and monitoring and inspections. We posit that it is possible to prevent proliferation of WMD by using intensified sanctions or increased monitoring and inspections. Secondly, increased sanctions lead to a decrease in monitoring activities without affecting inspections, while the increased benefits of monitoring allow such activities to increase without affecting inspections. Thirdly, if increased costs of development of WMD could sufficiently decrease the extent of inspection activities, they would also reduce the extent of monitoring activities.

This paper is organized as follows. In section 2, we set up a model of nonproliferation of WMD using a simple game theory, and in section 3, we examine the equilibrium of the model. In section 4 , we discuss the problem of WMD in Iraq and analyze two Security Council Resolutions regarding monitoring, inspections, and sanctions. In section 5, we consider the problem of nonproliferation of WMD in the context of Iraq from the point of view of international political circumstances, reputation effects, and supply controls. In section 6 , we summarize some conclusions.

\section{Model of Nonproliferation of WMD}

We set up a simple model to examine nonproliferation of WMD using monitoring, inspections, and sanctions. The model in this study expands the conventional deterrence theory as an aid to monitoring and inspections ${ }^{2}$. This model is a one-shot game model with four stages.

Players. Suppose there are two players in this game, the "UN Security Council" and the "potential proliferator". The UN Security Council is expressed as a representative of the international community, and its behavioral purpose is to prevent the potential proliferator from developing WMD under NPT, BWC, and CWC. The potential proliferator aims to develop WMD. In particular, the potential proliferators, who have tense relationships with their neighboring nations, are going to earn political and military advantages by developing WMD. We suppose that the UN Security Council and the potential proliferator are risk neutral.

Actions. We assume that the UN Security Council and the potential proliferator take the following actions. In this game, the UN Security Council has three chances to move, and the potential proliferator has one chance

\footnotetext{
1 The CWC includes a safeguard treaty, an additional International Atomic Energy Agency (IAEA) protocol for nuclear weapons, and rules of inspection (industrial verification and challenge inspection) for chemical weapons. Negotiations for establishing an inspection system for biological weapons, however, have now stopped.

${ }^{2}$ See Mookherjee and Png (1992) and Kaplow and Shavell (1994) for more details on monitoring and inspections. See Powell (1990), Nalebuff (1991), and Morrow (1994) for information on the deterrence theory. The model in this study mainly focuses on the issue of proliferation of nuclear weapons by potential proliferators.
} 
to move. One action of the potential proliferator is how many WMD it develops under the regimes of nonproliferation controlled by the UN Security Council. Actions of the UN Security Council consist of monitoring, inspections, and sanctions to prevent the potential proliferator from developing WMD. Monitoring is enforced to preempt the development of WMD by the potential proliferator. Inspections are enforced to verify the development of WMD after their development is exposed. The sanctions are imposed after the potential proliferators' development of WMD has been verified by the inspections. Sanctions may be of the economic and/or military kind.

Outcomes. Four international outcomes result from the actions undertaken by the UN Security Council and the potential proliferator. The first outcome is "effective monitoring" (V), in which the monitoring performed by the UN Security Council works effectively, and the potential proliferator does not develop WMD. The second is "failure of monitoring" (W), in which the monitoring performed by the UN Security Council is not effective, and the potential proliferator develops WMD that remain undiscovered. The third is the "failure of inspection" (X), in which the WMD developed by the potential proliferator are discovered but not verified by the inspections. The fourth is "enforcement of sanctions" (Y), wherein the UN Security Council imposes sanctions, and destroys the WMD and any related development programs after the development of the WMD is verified by the inspections.

The development of WMD by the potential proliferator will be prevented if the monitoring works effectively, or if the inspection and sanctions work as intended even if the monitoring is ineffective. However, the potential proliferator develops WMD if all three deterrents (monitoring, inspections, and sanctions) do not work effectively.

Payoff for the Security Council. We explain the payoff for the UN Security Council in each international outcome. Suppose that $e_{\mathrm{M}}$ represents monitoring costs to the UN Security Council, and $v$ indicates benefits that the UN Security Council receives when nonproliferation of WMD results from the monitoring. $e_{\mathrm{I}}$ denotes inspection costs; $(1+\theta) s$ refers to benefits of sanctions, where $s$ denotes sanctions against the potential proliferator; and $\theta$ refers to the effects of sanctions, where $\theta=\theta\left(s_{-1}\right)$ and $\theta^{\prime}>0$, which means that the current effects of sanctions depend on the sanctions imposed last time, $s_{-1}$. Now, we explain the reputation effect of sanctions in this model. Let $y$ represent disutility for the UN Security Council when the potential proliferator develops WMD. It is assumed that $y=y(x), y^{\prime}>0$, and $y^{\prime \prime} \geq 0$, where $x$ is the quantity of WMD developed by the potential proliferator.

Then, the payoffs for the UN Security Council in the four international outcomes are as follows. Effective monitoring $(\mathrm{V}):-e_{\mathrm{M}}+v$, failure of monitoring $(\mathrm{W}):-e_{\mathrm{M}}-y(x)$, failure of inspection $(\mathrm{X}):-e_{\mathrm{M}}-e_{\mathrm{I}}-y(x)$, and enforcement of sanctions $(\mathrm{Y}):-e_{\mathrm{M}}-e_{\mathrm{I}}-y(x)+(1+\theta) s$. The optimal outcome for the UN Security Council is effective monitoring (V) followed by enforcement of sanctions (Y), in which the UN Security Council imposes sanctions if the potential proliferator develops WMD. Failure of monitoring (W) and failure of inspection (X) are the third and last optimal outcomes, respectively. Therefore, the preference order of the UN Security Council $(R)$ is V, Y, W, and $\mathrm{X}$.

Payoff for the Potential Proliferator. Payoffs for the potential proliferator are assumed as follows. If the potential proliferator does not develop WMD, the payoff is 0 . If the country develops them, its benefits are $b$ and its costs are $c$, where $b-c>0$. If the benefits of development $b$ are assumed to be correlated to quantity $x$, then $b=x$. If the development of WMD is discovered and inspection sanctions are imposed as a result, their 
costs are $s$, where $0 \leq s \leq s_{\max }$. The level of maximum sanctions $s_{\max }$ differs depending upon the potential proliferator and is based on economic and political conditions and international political circumstances.

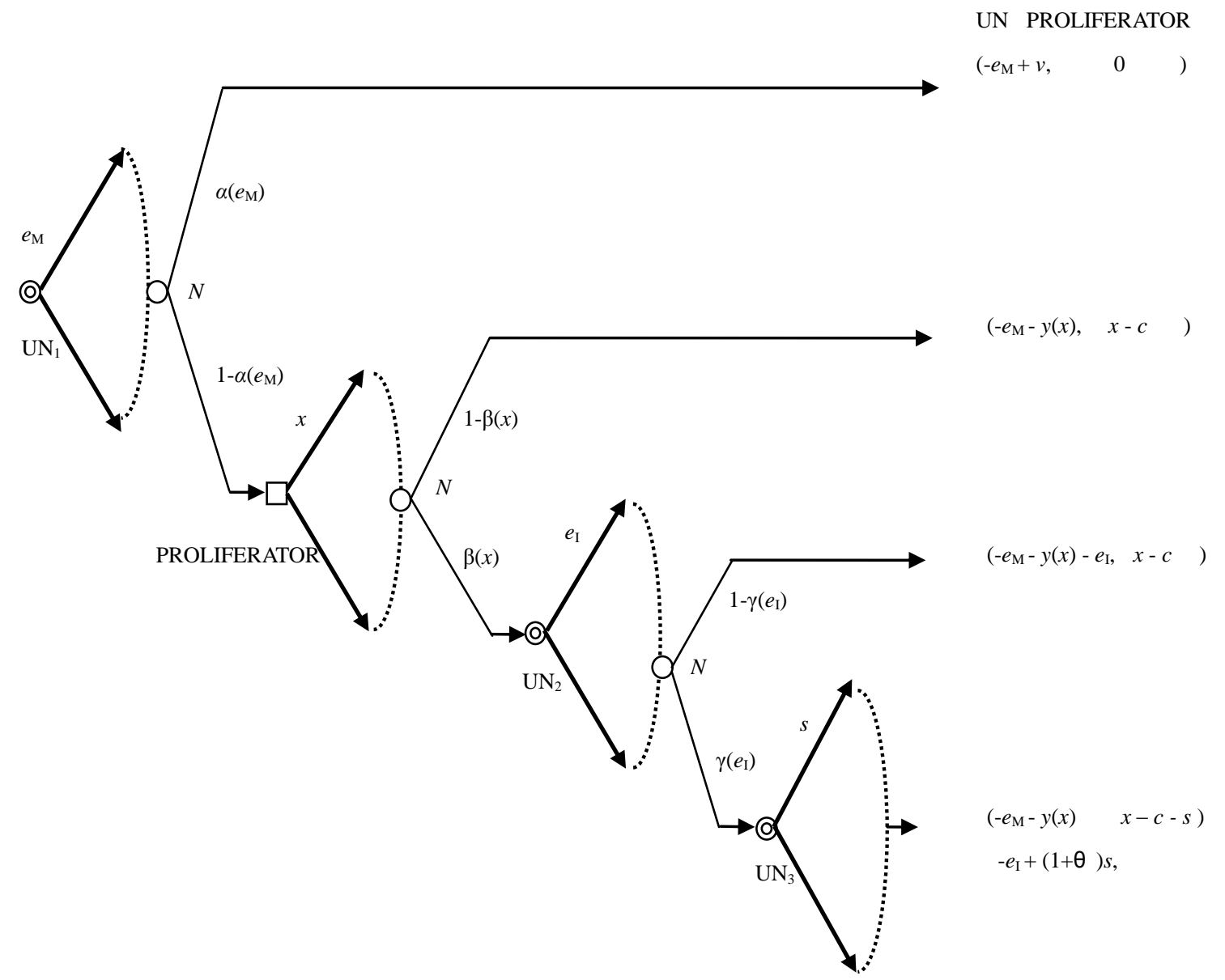

Figure 1. Model of nonproliferation of WMD.

Then, the payoffs for the potential proliferator in the four international outcomes are as follows. Effective monitoring $(\mathrm{V}): 0$, failure of monitoring $(\mathrm{W}): b-c$, failure of inspection $(\mathrm{X}): b-c$, and enforcement of sanctions (Y): $b-c-s$. The optimal outcome for the potential proliferator is either failure of monitoring $(\mathrm{W})$ or failure of inspection (X). The potential proliferator's preferences for effective monitoring $(\mathrm{V})$ or enforcement of sanctions (Y) depend on the relative effects between the net benefits of developing $b-c$ and the costs of sanctions $s$.

Timing of the Game and Information Structure. This game develops in the four stages as Figure1 shows ${ }^{3}$.

In the first stage, the UN Security Council decides to what extent it will enforce monitoring $e_{M}$ for nonproliferation of WMD. The probability that this monitoring works effectively is $\alpha$, and the probability that it does not work effectively is $1-\alpha$. It is assumed that $\alpha$ is a function of monitoring $e_{M}$, and thus, $\alpha=\alpha\left(e_{M}\right)$, where

\footnotetext{
3 As for Iraq after the Gulf War, the timing is different from our model because Iraq had already developed and used chemical weapons. According to Resolution 687 (April 1991), the UN expected to implement the following sequence. Firstly, Iraq was expected to make comprehensive declarations. Secondly, the UN inspectors were to verify them, and all items and activities that were prohibited were to be eliminated. Thirdly, the Security Council would have lifted the economic sanctions on Iraq. Fourthly, long-term monitoring would have continued (Blix, 2004, p. 100).
} 
$0 \leq \alpha \leq 1, \alpha^{\prime}>0$, and $\alpha^{\prime} \geq 0$. If the monitoring works effectively, the objective of nonproliferation of WMD has been achieved, and the game ends.

In the second stage, assuming that the monitoring is not effective, the potential proliferator determines how many WMD to develop. The probability of discovering this development is $\beta$ and that of not discovering it is $1-\beta$. Suppose that $\beta$ is a function of the development of WMD $x, \beta=\beta(x)$, where $0 \leq \beta \leq 1, \beta^{\prime}>0$, and $\beta^{\prime \prime} \leq$ 0 . If the potential proliferator increases the level of development, $x$, it increases the probability that the development is discovered by the monitoring conducted by the intelligence agencies of the UN member states aside from that of the UN. If the WMD are not discovered, the game ends.

In the third stage, we assume that the WMD are detected; then, the UN Security Council determines to what extent it should enforce inspection $e_{\mathrm{I}}$. This inspection verifies the development of WMD with probability $\gamma$ and does not verify it with probability $1-\gamma$. It is assumed that $\gamma$ is a function of inspection $e_{\mathrm{I}}$, and $\gamma=\gamma\left(e_{\mathrm{I}}\right)$, where $0 \leq \gamma \leq 1, \gamma^{\prime}>0$, and $\gamma^{\prime \prime} \leq 0$. If the WMD are not discovered by the inspection, the game ends.

In the fourth stage, if the inspection detects the WMD, the UN destroys them and determines what sanctions $s$ to enforce against the potential proliferator.

We suppose that the UN Security Council and the potential proliferator understand the above-mentioned situation. As they are uncertain whether the monitoring and inspections are working effectively, they share information on the values of $\alpha, \beta$, and $\gamma$.

\section{Equilibrium of the Nonproliferation Game of WMD}

What kind of relationships do sanctions have with monitoring and inspection? Firstly, we clarify the equilibrium of the nonproliferation game of WMD and then examine the effects that the sanctions have on monitoring and inspections.

\section{Equilibrium of the Game}

We assume that the equilibrium of the nonproliferation game of WMD is a sub-game perfect equilibrium that consists of the players' optimal strategies. We can resolve the equilibrium of the game by backward induction.

In the fourth and final stage, the UN Security Council imposes sanctions $s^{*}$ against the potential proliferator to maximize the payoff.

$$
s^{*}=\left\{\begin{array}{l}
\arg \max -e_{\mathrm{M}}-e_{\mathrm{I}}-y(x)+(1+\theta) s, \\
s_{\max } .
\end{array}\right.
$$

If the UN Security Council could verify the development of WMD, it would impose the maximum sanctions $s_{\max }$. Whether the sanctions are economic or military depends on particular circumstances. Then, the payoff of the potential proliferator is $x-c-s_{\max }$.

In the third stage, the inspection of the UN Security Council is determined as follows. The condition for the UN Security Council to enforce inspections is that the expected payoff $E_{\mathrm{UN} 0}$ of enforcing inspections exceeds the expected payoff $E_{\mathrm{UN} 1}$ of not enforcing them.

$$
E_{\mathrm{UN} 0}-E_{\mathrm{UN} 1}=\gamma(1+\theta) s_{\max }-e_{\mathrm{I}} \geq 0
$$

A participation constraint for the UN in enforcing the inspection is that the benefits of inspection $\gamma(1+$ 
$\theta) s_{\max }$ exceed the costs of inspection $e_{\mathrm{I}}$. Under this condition, the UN Security Council enforces the inspection to prevent the potential proliferator from developing WMD.

In the second stage, the condition that the potential proliferator does not develop WMD is that the expected payoff $E_{\mathrm{UH} 0}$ of developing the WMD is smaller than the expected payoff $E_{\mathrm{UH} 1}=0$ of not developing them. It is supposed that if $E_{\mathrm{NH} 0}$ equals $E_{\mathrm{NH} 1}$, the potential proliferator does not develop WMD. Then, the action of the potential proliferator is expressed as follows:

$$
\begin{cases}x^{*}=0 & \text { if } x-c-\beta(x) \gamma\left(e_{\mathrm{I}}\right) s_{\max } \leq 0 \\ \beta^{\prime}\left(x^{*}\right)=1 / \gamma\left(e_{\mathrm{I}}\right) s_{\max } & \text { if } x-c-\beta(x) \gamma\left(e_{\mathrm{I}}\right) s_{\max }>0\end{cases}
$$

The UN Security Council determines the level of inspection $e_{\mathrm{I}}{ }^{*}$ to prevent the potential proliferator from developing WMD under condition (2).

$$
\gamma\left(e_{\mathrm{I}}^{*}\right)=(x-c) / \beta(x) s_{\max }
$$

The optimal inspection $e_{\mathrm{I}}^{*}$ depends on the sanctions $s_{\max }$, the development level of WMD $x$, and the development $\operatorname{costs} c$. The level of inspection $e_{\mathrm{I}}{ }^{*}$ increases if the development of WMD $x$ is considerable. The level of inspection $e_{\mathrm{I}}^{*}$ decreases if the level of sanctions $s_{\max }$ and the costs of development $c$ are large.

In the first stage, the UN Security Council determines the level of monitoring $e_{\mathrm{M}}{ }^{*}$ to maximize the expected payoff subject to the following two conditions.

$$
\begin{gathered}
e_{\mathrm{M}}{ }^{*}=\arg \max -e_{\mathrm{M}}+\alpha\left(e_{\mathrm{M}}\right) v+\left(1-\alpha\left(e_{\mathrm{M}}\right)\right)\left[\beta\left(x^{*}\right)\left(\gamma\left(e_{\mathrm{I}}^{*}\right)(1+\theta) s_{\max }-e_{\mathrm{I}}^{*}\right)-y\left(x^{*}\right)\right] \\
\text { s.t. } \quad \alpha\left(e_{\mathrm{M}}\right)\left[y\left(x^{*}\right)-\beta\left(x^{*}\right)\left(\gamma\left(e_{\mathrm{I}}^{*}\right)(1+\theta) s_{\max }-e_{\mathrm{I}}^{*}\right)\right]+\alpha\left(e_{\mathrm{M}}\right) v-e_{\mathrm{M}} \geq 0 \\
x^{*}-c-\beta\left(x^{*}\right) \gamma\left(e_{\mathrm{I}}^{*}\right) s_{\max }=0
\end{gathered}
$$

The first of the two constraints is the condition that the UN Security Council participates in the monitoring. The second equation is the condition that the potential proliferator does not develop WMD. The optimal monitoring $e_{\mathrm{M}}{ }^{*}$ is determined by eq. (6). The denominator of eq. (6) is positive owing to the first constraint.

$$
\alpha^{\prime}\left(e_{\mathrm{M}}^{*}\right)=1 /\left[y\left(x^{*}\right)+v+\beta\left(x^{*}\right) e_{\mathrm{I}}^{*}-(1+\theta)\left(x^{*}-c\right)\right]
$$

The optimal monitoring $e_{\mathrm{M}}{ }^{*}$ of the UN Security Council depends on the inspection $e_{\mathrm{I}}{ }^{*}$, the effects of sanctions $\theta$, the benefits of monitoring $v$, the development of WMD $x^{*}$, and the costs $c$. The optimal monitoring

$e_{\mathrm{M}}{ }^{*}$ increases if the costs of development $c$ and the benefits of monitoring $v$ are large. However, the optimal monitoring $e_{\mathrm{M}}{ }^{*}$ reduces if effects of sanctions $\theta$ are large.

The following are the relationships among the sanctions, inspections, and monitoring. As for the sanctions, the maximum extent of sanctions $s_{\max }$ is decided by the payoff maximization of the UN Security Council. After the level of sanctions $s_{\max }$ is determined, inspection $e_{\mathrm{I}}{ }^{*}$ is undertaken to prevent the potential proliferator from developing WMD. Monitoring $e_{\mathrm{M}}{ }^{*}$ is intended to maximize the expected payoff according to sanctions $s_{\max }$ and inspection $e_{\mathrm{I}}{ }^{*}$.

\section{Relationships Among Sanctions, Monitoring, and Inspections}

What kind of effects will the sanctions have on the monitoring and inspections? We have the following 
proposition with regard to the relationships among sanctions, monitoring, and inspections.

Proposition 1. There is a substitutive relationship between the sanctions and monitoring and inspections. The proliferation of WMD is deterred by using intensified sanctions or increasing monitoring and inspections.

Proof. By eq. (1), the UN Security Council imposes the maximum sanctions $s_{\max }$ for the potential proliferator. If the upper limit $s_{\max }$ of the sanctions is decreased, the extent of inspection $e_{\mathrm{I}}^{*}$ determined by eq. (4) increases. The increased inspection $e_{\mathrm{I}}{ }^{*}$ augments the level of monitoring $e_{\mathrm{M}}{ }^{*}$ determined by eq. (6).

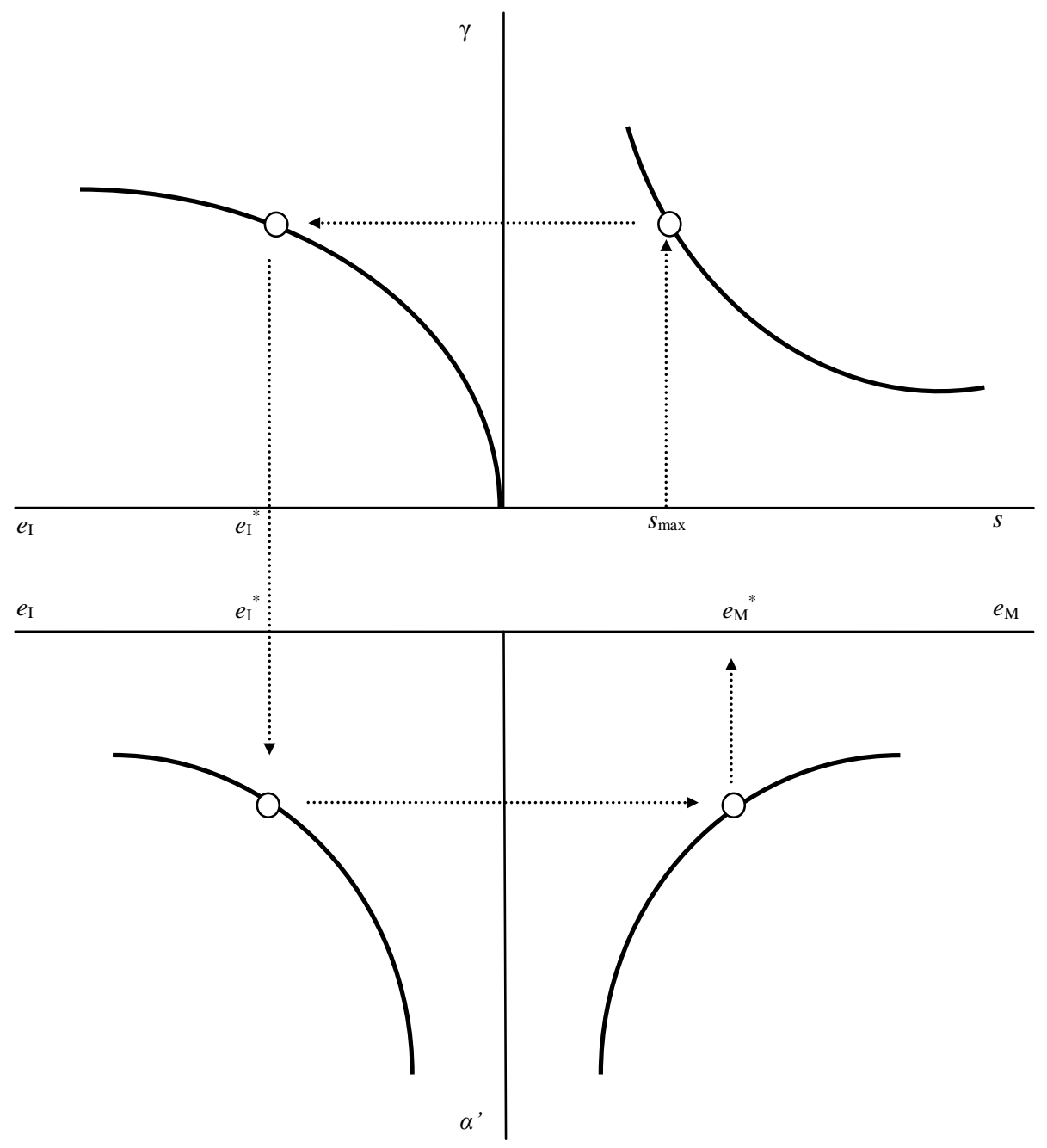

Figure 2. Sanctions, monitoring, and inspections.

Figure 2 expresses the relationship among the sanctions, monitoring, and inspections. As the first quadrant in Figure 2 shows, there is the substitutive relationship between sanctions $s$ and efficiency of inspection $\gamma$. The increased sanctions $s$ lead to a fall in the efficiency of inspection $\gamma$. As a result, they enable a fall in the level of inspection $e_{\mathrm{I}}{ }^{*}$, which is expressed in the second quadrant. The curve in the second quadrant is explained by the assumptions for $\gamma$, where $\gamma^{\prime}>0$ and $\gamma^{\prime \prime} \leq 0$. The marginal efficiency of monitoring $\alpha$ ' is in inverse proportion to inspection $e_{\mathrm{I}}{ }^{*}$, as shown in the third quadrant. The curve in the fourth quadrant expresses a relationship between monitoring $e_{\mathrm{M}}{ }^{*}$ and marginal efficiency of monitoring $\alpha^{\prime}$, and the latter is diminishing assuming that $\alpha^{\prime}>0$ and $\alpha " \leq 0$. Observing the third and fourth quadrants makes it clear that there is a positive relationship between 
inspection $e_{\mathrm{I}}{ }^{*}$ and monitoring $e_{\mathrm{M}}{ }^{*}$. In this way, we can understand that sanctions $s$ have a substitutive relationship with monitoring $e_{\mathrm{M}}{ }^{*}$ and inspection $e_{\mathrm{I}}{ }^{*}$.

What kind of impact will the sanctions $\theta$, monitoring $v$, and development costs of WMD $c$ have on inspection and monitoring? Accordingly, we make the following propositions.

Proposition 2. The increased effect of sanctions $\theta$ has no impact on inspections $e_{\mathrm{I}}^{*}$, on the one hand, while it decreases the level of monitoring $e_{\mathrm{M}}{ }^{*}$. On the other hand, the increased benefits of monitoring $v$ have no effect on inspections $e_{\mathrm{I}}{ }^{*}$, while they increase the level of monitoring $e_{\mathrm{M}}{ }^{*}$.

Proof. The impacts of the increased effect of sanctions $\theta$ and the increased benefits of monitoring $v$ on monitoring $e_{\mathrm{M}}{ }^{*}$ and inspection $e_{\mathrm{I}}^{*}$ are as follows:

$$
\begin{gathered}
\partial e_{\mathrm{M}}{ }^{*} / \partial \theta=(x-c) / \alpha "\left[y(x)+v+\beta(x) e_{\mathrm{I}}^{*}-(1+\theta)(x-c)\right]^{2}<0, \\
\partial e_{\mathrm{M}}{ }^{*} / \partial v=-1 / \alpha "\left[y(x)+v+\beta(x) e_{\mathrm{I}}^{*}-(1+\theta)(x-c)\right]^{2}>0, \\
\partial e_{\mathrm{I}}^{*} / \partial \theta=\partial e_{\mathrm{I}}^{*} / \partial v=0 .
\end{gathered}
$$

Proposition 3. The increased development costs of WMD $c$ decrease the level of inspection $e_{\mathrm{I}}^{*}$. If inspection $e_{\mathrm{I}}{ }^{*}$ decreases sufficiently, then monitoring $e_{\mathrm{M}}{ }^{*}$ decreases.

Proof. The effects of the increased development costs $c$ on monitoring $e_{\mathrm{M}}{ }^{*}$ and inspection $e_{\mathrm{I}}{ }^{*}$ are obtained as follows:

$$
\begin{gathered}
\partial e_{\mathrm{M}}{ }^{*} / \partial c=-\left[\beta\left(\partial e_{\mathrm{I}}{ }_{\mathrm{I}}^{*} / \partial c\right)+(1+\theta)\right] / \alpha^{\prime}\left[y(x)+v+\beta(x) e_{\mathrm{I}}{ }^{*}-(1+\theta)(x-c)\right]^{2}, \\
\begin{cases}\leq 0 & \text { if } \beta\left(\partial e_{\mathrm{I}}^{*} / \partial c\right)+(1+\theta) \leq 0, \\
>0 & \text { if } \beta\left(\partial e_{\mathrm{I}}^{*} / \partial c\right)+(1+\theta)>0,\end{cases} \\
\partial e_{\mathrm{I}}{ }^{*} / \partial c=-1 / \gamma^{\prime} \beta s_{\max }<0 .
\end{gathered}
$$

The effects of the increased development costs of WMD $c$ on monitoring $e_{\mathrm{M}}{ }^{*}$ depend on the relative sizes of $\beta\left(\partial e_{\mathrm{I}}{ }^{*} / \partial c\right)$ and $(1+\theta)$. If increased development costs $c$ sufficiently decrease inspection $e_{\mathrm{I}}{ }^{*}$, they reduce monitoring $e_{\mathrm{M}}{ }^{*}$.

\section{Monitoring, Inspections, and Sanctions: The Case of Iraq}

What kinds of relationships actually exist among monitoring, inspection, and sanctions? We examine these relationships in the context of Iraq's WMD.

\section{Background of Monitoring, Inspections, and Sanctions in the Case of Iraq's WMD}

We briefly describe the monitoring, inspections, and sanctions with regard to WMD in Iraq.

Inspection and Destruction of Iraqi WMD. Iraqi WMD comprised nuclear weapons and fissionable materials, chemical weapons, biological weapons, and ballistic missiles carrying them. The inspections and dismantlement of nuclear weapons and fissionable materials was undertaken by the International Atomic Energy Agency (IAEA), leading to the founding of the IAEA Iraq Action Team. For the other materials, the United Nations Special Commission (UNSCOM) was charged with the issue from 1991 to 1998, and United 
Nations Monitoring, Verification and Inspection Commission (UNMOVIC) handled the same after $1999^{4}$.

Firstly, with regard to nuclear weapons and fissionable materials, Iraq had learned how to enrich uranium; however, its enrichment level and industrial capacity were very low (Blix, 2004, p. 18, p. 178). Iraq had a nuclear weapons development program, but there was no evidence that Iraq had succeeded in developing nuclear weapons. The IAEA studied the entire Iraqi nuclear weapons program, destroyed its infrastructure, and removed all fissionable materials from Iraq. The IAEA reported that there was no unresolved disarmament issue for nuclear weapons and fissionable materials, but various technical questions remained ${ }^{5}$.

Secondly, Iraq got involved in the research and development (R\&D) and production of various chemical weapons, including Tabun, Sarin, Mustard, VX, Soman, and BZ, and biological weapons, including Anthrax, Botulinum Toxin, Mycotoxins, Clostridium Perfringens, and Ricin. Iraq denied producing biological weapons at first; however, it admitted to their production in 1995. As for ballistic missiles, Iraq had Scud-type missiles, SA-2 missile technology, Al Samoud 2 missiles, FROG special warheads, and conducted R\&D on ballistic missiles capable of proscribed ranges and on solid propellant missile systems.

UNSCOM and UNMOVIC supervised much of the destruction of chemical and biological weapons, ballistic missiles, weapon-related materials, production devices, and institutions ${ }^{6}$. However, Iraq did not offer enough accurate evidence related to the production and consumption of weapons and weapon-related materials. In addition, the UN inspectors were not able to verify the contents of Iraqi declarations that Iraq had unilaterally disposed of weapons without the supervision of the UN inspectors. Therefore, before the Iraq War, UNSCOM and UNMOVIC were not able to deny the possibility that there were non-declared biological and chemical weapons in $\operatorname{Iraq}^{7}$.

Background of Monitoring, Inspections, and Sanctions in Iraq. Security Council Resolutions 687 and 1284, Inspections, and Monitoring. After the Gulf War, a containment policy was adopted for Iraq according to Security Council Resolution 687. Thorough inspections, monitoring, and economic sanctions on WMD were enforced. Later, Resolution 687 was supplemented by Resolution 1284.

On April 3, 1991, UNSCOM was founded on the basis of Security Council Resolution 687. The purpose of this special committee was the inspection and disposal of all WMD except nuclear weapons and fissionable materials in Iraq. As for nuclear weapons and fissionable materials, the Iraq Action Team was established within the IAEA on April 15 of the same year. Resolution 687 gave UN inspectors the power to conduct highly intrusive inspections and maintain a robust monitoring system ${ }^{8}$. By Resolution 687 , the IAEA demanded that Iraq eliminate all WMD, production devices and institutions, and development plans. In addition, it was decided that until all prohibited items, production devices and institutions, and development programs were

\footnotetext{
4 See Ritter (1999) and Blix (2004) for the UN inspections in Iraq.

5 The IAEA submitted a report (S/1997/779) to the UN Security Council in October 1997. This report explains the activities of the IAEA from April 1991 to October 1997. The IAEA revised and summarized the report and drew up a new report (S/1998/927) in October 1998 and one (S/1999/393) in April 1999 regarding UN activity until 1998 (IAEA, 2002b).

6 On March 6, 2003, UNMOVIC released a cluster of documents regarding WMD in Iraq (UNMOVIC, 2003). The documents led to a revision of the report by UNSCOM in 1999, reflecting the changes in the situation after 1999.

7 After the Iraq War, the Iraq Survey Group, which belonged to the US, evaluated the situation in Iraq. See Kerr (2004a) for claims on Iraqi WMD by the Bush Administration and the problems associated with it.

8 The inspections based on the safeguards of the IAEA were limited to declared places; however, Resolution 687 gave the UN inspectors the right of access to all places and persons. In 1997, the IAEA adopted "additional protocols" to strengthen the safeguard systems of the declarations and inspections. See Goldschmidt (1999), IAEA (2002a, 2003a), and Hooper (2003) for details about the IAEA safeguard system.
} 
eliminated, economic sanctions would be imposed on Iraq ${ }^{9}$.

Table 1.

Monitoring, Inspections, and Sanctions on Iraqi WMD

\begin{tabular}{|l|l|}
\hline $8 / 2 / 1990$ & Iraqi invasion of Kuwait \\
\hline $1 / 17 / 1991$ & The Gulf War $(1 / 17-2 / 28)$ \\
\hline $4 / 3 / 1991$ & Security Council Resolution 687, UNSCOM, and economic sanctions \\
\hline $8 / 14 / 1995$ & Security Council Resolution 986, Oil-for Food Program \\
\hline $12 / 17 / 1998$ & Iraq refuses to cooperate with UN inspections \\
\hline $12 / 17 / 1999$ & Operation Desert Fox by the US and UK (12/17-12/20) \\
\hline $11 / 29 / 2001$ & Security Council Resolution 1284, UNMOVIC \\
\hline $9 / 16 / 2002$ & Security Council Resolution 1382, smart sanctions \\
\hline $11 / 8 / 2002$ & Iraqi acceptance to reopen UN inspections \\
\hline $11 / 27 / 2002$ & Security Council Resolution 1441 \\
\hline $3 / 20 / 2003$ & UN inspections reopened for Iraq \\
\hline & The Iraq War (3/20-5/1) \\
\hline
\end{tabular}

The UN inspections achieved many results at an early stage. The inspections conducted between May and July 1991 confirmed that Iraq had enriched uranium. In June of the same year, a truck carrying nuclear development-related devices was discovered, and in September, documents on an Iraqi nuclear program were confiscated. The IAEA removed all fissionable materials from Iraq after 1992, transported them to Russia, and supervised the destruction of many nuclear weapons-related installations (Blix, 2004, p. 28). As General Hussein Kamal, who had responsibility for all Iraqi weapons programs until his defection to Jordan in August 1995, further clarified the reality of Iraqi nuclear programs, Iraq's government submitted documents relating to its nuclear programs to the UN inspectors. The documents verified that Iraq had encouraged a program of biological weapons development and that Kamal ordered the establishment of a nuclear weapons program in August $1990^{10}$.

The UN inspections were stopped by Iraqi refusal at the end of 1998. In July 1998, the Iraqi declaration for biological and chemical weapons was deemed questionable by UN inspectors. Iraq expressed disapproval of the indication, and in August of the same year, refused cooperation to the UN inspections. In response, on December 17 of the same year, the US and UK launched Operation Desert Fox in Iraq. The day before, the UN inspectors had left Iraq and the inspection by UNSCOM was virtually finished. Thereafter, Iraq refused entrance to the UN inspectors unless the economic sanctions were removed.

On December 17, 1999, UNMOVIC was founded in place of UNSCOM according to Security Council Resolution 1284. The purpose and authority of this committee were basically the same as those of UNSCOM. The IAEA Iraqi Action Team continued to hold charge of the inspection of nuclear weapons and fissionable materials $^{11}$. After February 2001, talks between the UN Secretary General and Iraq resumed toward the reopening of the UN inspections, and on September 16, 2002, Iraq agreed to the reopening.

Security Council Resolution 1441 and Military Sanctions. After the passage of Security Council Resolution

\footnotetext{
9 On April 14, 1995, the Oil-for-Food Program was enforced according to Resolution 986 and economic sanctions on Iraq were relaxed. Furthermore, on November 29, 2001, "smart sanctions" were decided by Resolution 1382.

10 At a hearing of UNSCOM and the IAEA, Hussein Kamal (one of Saddam Hussein's sons-in-law) stated that he ordered the destruction of all biological and chemical weapons in the summer of 1991 (Blix, 2004, p. 29). The Iraqi government repeated a similar claim but did not submit reliable evidence later to prove it.

11 On December 1, 2002 the IAEA Iraq Action Team was renamed the Iraq Nuclear Verification Office (INVO).
} 
1441 and realizing the continuing difficulties surrounding the UN inspections, military pressures by US Military forces increased, leading to military sanctions and, finally, the Iraq War.

On September 11, 2001, synchronized terrorist attacks occurred in the US. After the terrorist attacks, there was a huge change in American security policies ${ }^{12}$. On September 17, 2002, in The National Security Strategy of the United States (White House, 2002a), the US supported the concept of preemptive action and suggested the possible use of nuclear weapons (White House, 2002b). The US and UK made public announcements of reports about Iraqi WMD to coincide with the UN General Assembly in September $2002^{13}$.

Security Council Resolution 1441, reflecting the US position, was adopted on November 8, 2002. The inspection authority of UNMOVIC and IAEA was reinforced by the resolution ${ }^{14}$. On November 13, Iraq accepted Resolution 1441, and UN inspections resumed. The new declaration submitted by Iraq was examined in the UN Security Council on December $19^{15}$. Regarding for the Iraqi declaration, UNMOVIC and IAEA reported that many parts were the same as the report that had already been submitted, and there was no evidence or material that indicated a resolution of any of the pending disarmament issues (Blix, 2004, p. 108).

On February 14, 2003, UNMOVIC reported the following at a special meeting of the Security Council. While WMD were not discovered in Iraq, many prohibited weapons and other items were unaccounted for ${ }^{16}$, and the Iraqis had failed to present credible evidence in support of their contention. The IAEA identified some technical questions at the same meeting but did not indicate any unresolved disarmament issues with regard to the nuclear weapons. On January 27, the IAEA reported that, by 1992, it had largely destroyed, removed, or rendered harmless all Iraqi facilities and equipment relevant to nuclear weapons production, and that by 1994, it had removed all fissionable materials from Iraq (Blix, 2004, pp. 140-141, p. 178).

While the UN inspections continued, on March 7, 2003, the UK announced an amendment in the Security Council to the draft resolution expressed by the UK, the US, and Spain on February 24. The amendment proposed that the Council demand a strategic decision for Iraq to turn in all WMD and that the Council use armed action if it could not confirm the decision by a fixed date. The draft resolution was withdrawn afterwards, however, because there was no possibility of its adoption by the Security Council. At the same Security Council meeting, the French, German, and Russian ministers advocated continuing the UN inspections according to the proposals they had declared in Paris some days earlier.

On March 17, 2003, France demanded that the Council evaluate the results of UN inspections on the basis of Resolution $1284^{17}$. In contrast, the US asserted that Iraq had not fulfilled its obligations to disarm under binding Security Council resolutions and that this entitled individual members of the Council to take action

\footnotetext{
12 In January 2002, President Bush named Iraq, Iran, and North Korea as an "axis of evil" in his State of the Union address. Preparations for the Iraq War, however, had begun before then (Woodward, 2004).

13 The reports of the US and UK pointed out that an illegally imported aluminum pipe was a part of a centrifuge device used for uranium enrichment. In addition, the UK report shed light on the uranium import scandal (Blix, 2004, p. 232). In October 2002, the Central Intelligence Agency (CIA) published its National Intelligence Estimate, and this CIA report formed a foundation for the US evaluation of Iraqi WMD.

14 The authority for inspection prescribed by the Security Council limited inspection modalities for sensitive sites (Jun 23, 1996) and presidential sites (February 23, 1998). Thereafter, UNMOVIC did away with the first modality. In addition, Resolution 1441 placed the presidential sites on par with the other sites.

${ }^{15}$ The US ambassador pointed out that there was no information about mobile biological weapons facilities, procurement of uranium, and unmanned aerial vehicles in the Iraqi declaration to the UN Security Council (Blix, 2004, p. 108).

16 After reopening the inspections in November 2002, about 300 inspections were enforced at more than 230 different sites over a two-month period (Blix, 2004, p. 140), but there were many unresolved issues.

17 On January 17, 2003, President Chirac personally affirmed to UNMOVIC executive director Hans Blix that Iraq had no WMD, which proved the effectiveness of the UN inspections, and that war was, consequently, the worst solution (Blix, 2004, p. 128).
} 
without the need for any collective decision by the Council ${ }^{18}$ (Blix, 2004, p. 9). Subsequently, the US and the UK commenced the Iraq War to enforce military sanctions ${ }^{19}$.

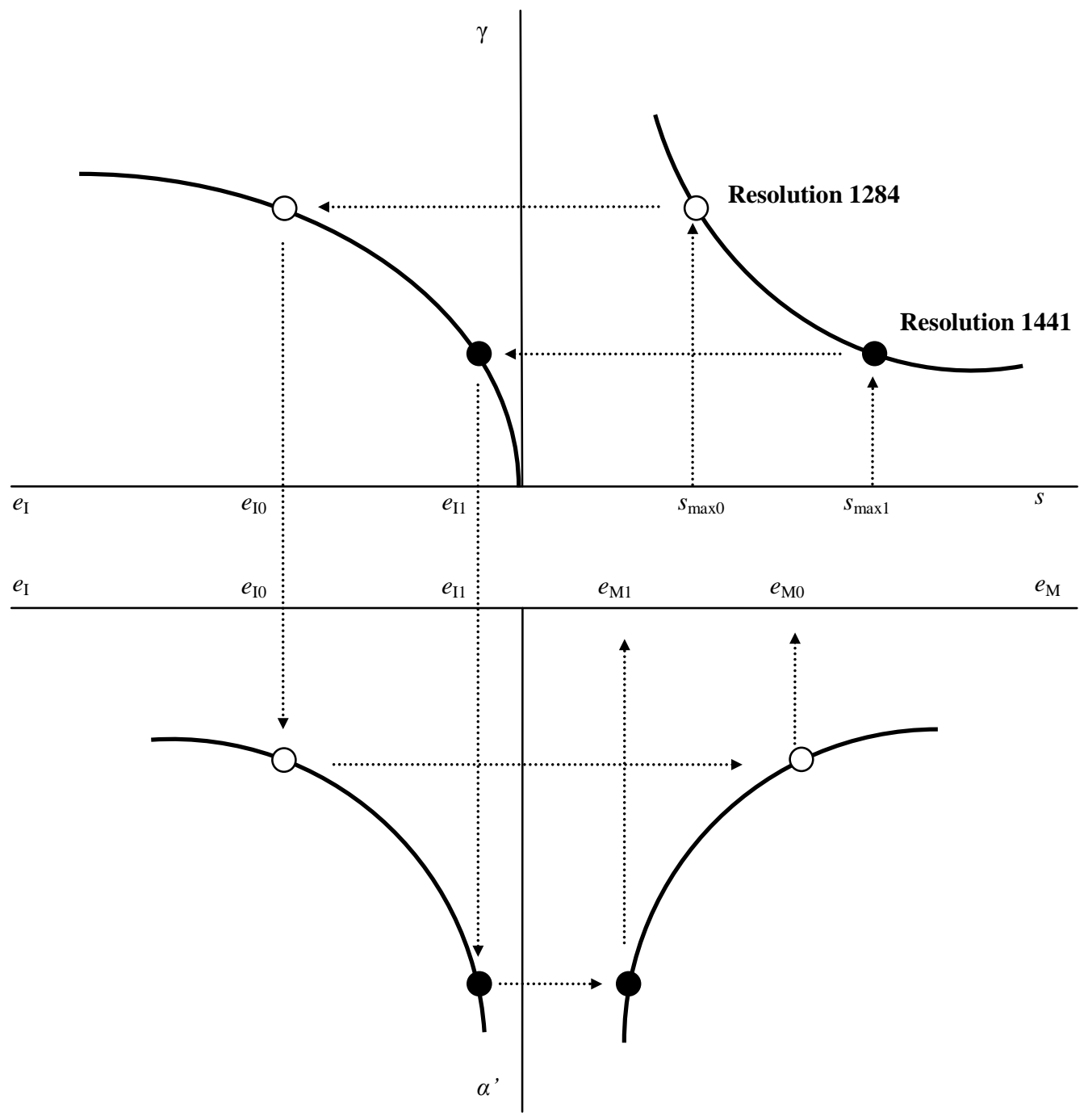

Figure 3. Comparison of Security Council Resolutions 1284 and 1441

\section{Two Security Council Resolutions}

Security Council Resolutions 1284 and 1441 contrast each other with regard to monitoring, inspections, and sanctions. According to Proposition 1, the destruction of WMD can be realized by strengthening monitoring and inspection, or by enforcing increased sanctions. Security Council Resolution 1284 attaches more importance to monitoring and inspection than military sanctions, while Security Council Resolution 1441 advocates military sanctions. Just before the Iraq War, France, Germany, and Russia demanded, based on

\footnotetext{
18 See Buchwald (2003), Taft IV and Buchwald (2003), and Yoo (2003) for justification of the actions of the US from the point of view of international law.

19 The model proposed in this study follows the assertions of France, Germany, and Russia; namely, it is assumed that the Security Council evaluates the UN inspections and decides upon sanctions according to the evaluation. However, in the case of the Iraq war, the US and UK evaluated the investigation and imposed military sanctions independently.
} 
Resolution 1284, that the UN discern a set of benchmarks for Iraq to give up its WMD, and demanded that Iraq to satisfy them and agree to inspections. Moreover, the US and UK demanded the "strategic decision" on abolishment of WMD in Iraq according to Resolution 1441 and asserted that they could use armed action if it could not be confirmed. Figure 3 shows a comparison of these two resolutions in our model.

Resolution 1284 is a policy of "containment" consisting of monitoring, inspections, and economic sanctions, and is expressed by the set $\left(s_{\max 0}, e_{\mathrm{I} 0}, e_{\mathrm{M} 0}\right)$ in Figure 3 . This resolution supplements Resolution 687 that prescribes UN inspection and monitoring of Iraqi WMD. While Resolution 687 advocates the complete lifting of all economic sanctions after all prohibited weapons are completely eradicated, Resolution 1284 opens the possibility for a suspension of sanctions in return for Iraqi cooperation in all respects, leading to progress in resolving "key remaining disarmament tasks". France, Germany, and Russia asserted that the remaining disarmament issues should be prioritized based on this Resolution, with detailed time lines being set for each issue (Blix, 2004, p. 39, p. 206).

Resolution 1441 follows the policy of "counter-proliferation", which attaches importance to military sanctions rather than monitoring and inspections. It is expressed by the set $\left(s_{\max 1}, e_{\mathrm{I} 1}, e_{\mathrm{M} 1}\right)$ in Figure 3 . This resolution called on Iraq to submit a "currently accurate, full, and complete declaration". "False statements or omissions shall constitute further material breach", which could lead to "serious consequences". Based on Resolution 1441, the US and the UK judged that Iraq did not fulfill its obligations and asserted that they had the authority to impose military sanctions against Iraq. At the time, rather than rely on the evidence available through inspections, the US was only concerned about the "strategic decision" that Iraq abolishes all its WMD.

\section{After the Iraq War}

What kind of implication does our model have for monitoring, inspections, and sanctions regarding WMD after the Iraq War? We examine the effects of efforts aimed at nonproliferation of WMD for potential proliferators from the viewpoint of international political relations, reputation effect, and supply control.

\section{International Political Relations and Reputation Effects}

International Political Relations. After the nuclear issue was revived in October 2002, North Korea declared its withdrawal from the NPT and refused inspections by the IAEA ${ }^{20}$. The North Korean nuclear issue resulted in six-party talks that included North Korea, the US, China, Russia, South Korea, and Japan. This situation differed from the case of Iraq.

In October 2002, North Korea was detected pursuing a nuclear development program using uranium enrichment. After this discovery, the Korean Peninsula Energy Development Organization (KEDO) stopped the supply of heavy oil to North Korea. Against the procedure, North Korea refused to let IAEA monitor its nuclear sites and storage of nuclear rods, and declared its withdrawal from NPT in January 2003. Then, North Korea resumed operation of its experimental furnaces and started rehandling nuclear rods. Six-party talks were held in August 2003 to address the North Korean nuclear issue ${ }^{21}$.

International political opinion with regard to the sanctions on North Korea was divided. China and Russia objected to reinforcement of US sanctions, including military sanctions, on North Korea. As a result, the level

\footnotetext{
${ }^{20}$ See Mazarr (1995), Sigal (1998), Niksch (2002), and Kerr (2004b) for information on the North Korean nuclear issue.

21 The six-party talks did not work as intended. In their third session (June 2004), the US proposed the complete abandonment of North Korea's nuclear programs (Kelly, 2004). However, North Korea brushed off the suggestion and conducted five more nuclear tests (October 2006, May 2009, February 2013, January 2016, and September 2016).
} 
of sanctions $s_{\max }$ on North Korea was lower compared to the case of Iraq. The difference in such sanctions is evident as the difference in inspections $e_{\mathrm{I}}{ }^{*}$ and monitoring $e_{\mathrm{M}}{ }^{*}$ (see Proposition 1). In other words, to prevent North Korean nuclear development programs, it will be necessary for the IAEA to strengthen monitoring and inspection activities for North Korea. It is also essential that North Korea abide by the NPT and that it accepts the "additional protocol", accepting surprise inspections and inspections at non-declared sites by the IAEA.

Reputation Effects. What kind of influence did the proponents of the Iraq War believe that the armed action in Iraq would have for the monitoring, inspection, and sanctions regarding WMD on potential proliferators $^{22}$ ? The UK's Prime Minister Blair pointed out that the Iraq conflict would send a message to North Korea (Blix, 2004, p. 130). This belief places special emphasis on the reputation effect, and Libya and Iran were mentioned as potential proliferators ${ }^{23}$.

The UK pushed forward talks with Libya for disarmament of its WMD from March 2003. Libya had violated the safeguard agreements of the IAEA from the beginning of the 1980s to the end of 2003, and had acquired nuclear materials and embarked on a nuclear program. On December 19, 2003, Libya declared the abolishment of its nuclear program and its acceptance of inspections, and later signed the "additional protocol" (Blix, 2004, p. 160). It was thought that by forcing military sanctions on Iraq, the UK expected the reputation effect to come into play for Libya. In international political relations, the case of Libya was more similar to that of Iraq rather than that of North Korea, as there was the possibility of imposing military sanctions on Libya.

The reputation effect on potential proliferators is expressed by the effect of sanctions $\theta$ in the model. In Figure 4, we explain the effects that the increased sanctions $\theta$ have on the monitoring and inspections. Assuming that $\theta=\theta\left(s_{-1}\right)$ and $\theta^{\prime}>0$, if we do not impose the sanctions $s_{-1}$ on Iraq at this time, we cannot have enough of a reputation effect $\theta$ in the future. On the contrary, we can have a large reputation effect $\theta$ in the future if we impose sufficient sanctions $s_{-1}$ on Iraq at this time. In Figure 4, the increased reputation effect $\theta$ shifts the curve $e_{\mathrm{I}} \alpha^{\prime}$ outward in the third quadrant and decreases the future monitoring cost $e_{\mathrm{M}}{ }^{*}$ in the fourth quadrant (see Proposition 2). In Figure 4, ○ expresses an initial state and (O) indicates the state after the increased reputation effect. There is a substitutive relationship between the current sanctions and future monitoring. This leads to a logical rationalization of military sanctions.

\section{Supply Control}

The "Action Plan on Nonproliferation" was adopted at the Sea Island Summit (G8) in June 2004. This action plan indicated some reinforcement of technical export control regulations on machineries and materials related to uranium enrichment and plutonium extraction. The export control regulation raises costs of acquisition, transportation, and production of WMD as well as the costs of development in the model.

Regarding the export control regulations of WMD and their delivery, we refer to the Nuclear Suppliers Group (Part 1: 1978, Part 2: 1992) and Zangger Committee (1974) for nuclear weapons, the Australian Group (1985) for chemical and biological weapons, and the Missile Technology Control Regime (1987) for ballistic missiles. The effects of the Comprehensive Test Ban Treaty and the Fissile Material Cut-Off Treaty will serve to increase the costs of development of nuclear weapons.

\footnotetext{
${ }^{22}$ See Carter and Perry (1999) and Litwark (2000) for details about the US policy for potential proliferators after the Cold War.

${ }^{23}$ Iran declared its nuclear program in February 2003. It expressed willingness to stop its nuclear program and to sign the additional protocol in exchange for energy cooperation from the UK, Germany, and France in October of the same year. See IAEA (2003b) and IAEA (2004) for an account of the nuclear programs in Iran and Libya, respectively.
} 


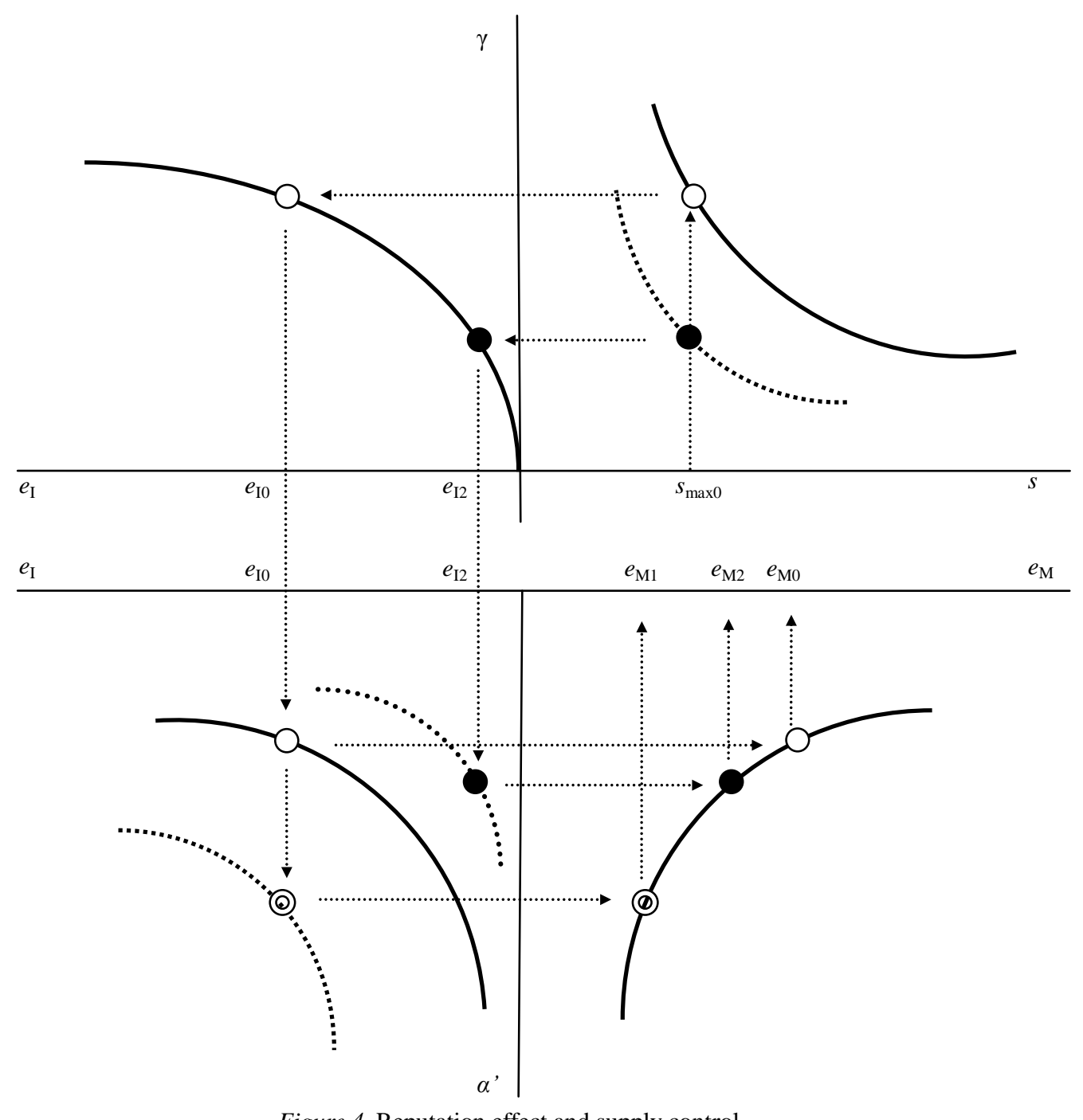

Figure 4. Reputation effect and supply control.

Notes. $\bigcirc$ : initial state, $\bigcirc$ : reputation effect,

We confirm the effects that the costs of development of WMD $c$ have on inspection $e_{\mathrm{I}}{ }^{*}$ and monitoring $e_{\mathrm{M}}{ }^{*}$ in Figure 4. The increased costs of development cause the curve $\gamma s_{\max }$ to shift inward in the first quadrant and decrease the efficiency of inspections $\gamma$. As a result, they decrease the level of inspections $e_{\mathrm{I}}{ }^{*}$, as expressed in the second quadrant. The effect that the increased costs of development have on monitoring $e_{\mathrm{M}}{ }^{*}$ is dependent on relative effects between the influence $(1+\theta)$ of the increased costs of development, shifting the curve $e_{\mathrm{I}} \alpha$ ' inward, and the impact $\beta\left(\partial e_{\mathrm{I}}^{*} / \partial c\right)$ of cost $c$ decreasing the number of inspections. These effects are expressed in the third quadrant. If the increased costs of development decrease inspection $e_{\mathrm{I}}^{*}$ sufficiently, they decrease monitoring $e_{\mathrm{M}}{ }^{*}$ (see Proposition 3). In Figure 4, • expresses the state of the increased costs of development of WMD.

\section{Concluding Remarks}

We examined the relationships among monitoring, inspections, and sanctions in the nonproliferation of 
WMD. In particular, we considered the effects of sanctions on monitoring and inspections.

Our main conclusions are summarized as follows. Firstly, there is a substitutive relationship between sanctions, monitoring, and inspections. This means that the proliferation of WMD can be prevented by imposing intensified sanctions or increasing monitoring and inspections. Differences in international political relations lead to different outcomes with regard to monitoring, inspections, and sanctions.

Secondly, the increased effect of sanctions decreases monitoring without affecting inspections, while the increased benefits of monitoring do not affect inspections. In case the effect of future sanctions is influenced by the current sanctions (reputation effect), the strengthened current sanctions increase the effect of future sanctions and decrease the cost of future monitoring. This rationalizes the need for military sanctions.

Thirdly, if the increased costs of developing WMD could decrease the number of inspections sufficiently, they would reduce monitoring activities. If the export control regulation increases the costs of development for potential proliferators and decreases the level of inspection by a sufficient level, the level of monitoring will reduce.

Finally, we propose a future research program. In the model used in this study, we assumed that the UN Security Council is unified, and that it evaluates the monitoring and inspections, and judges the sanctions. With regard to the Iraq War, however, France, Germany, and Russia insisted that the evaluation of the UN inspections and judgment regarding sanctions be conducted and passed, respectively, by the UN Security Council, while the US and UK did the same independently. We thus need to examine the problems arising from divisions in the UN.

\section{References}

Blix, H. (2004). Disarming Iraq. New York: Pantheon Books.

Carter, A. B., \& Perry, W. J. (1999). Preventive defense: A new security strategy for America. Washington, D.C.: Brookings Institution.

Goldschmidt, P. (1999). The IAEA safeguards system moves into the 21st century. IAEA Bulletin (Supplement), 41, S1-S19.

Hooper, R. (2003). The changing nature of safeguards. IAEA Bulletin, 45, 7-11.

IAEA. (2002a). Non-proliferation of nuclear weapons and nuclear security: IAEA safeguards agreements and additional protocols. Vienna: IAEA.

IAEA. (2002b). Fact sheet: Iraq's nuclear weapon programme. Vienna: IAEA.

IAEA. (2003a). The safeguards system of the International Atomic Energy Agency (“The Agency"). Vienna: IAEA.

IAEA. (2003b). Implementation of the NPT Safeguards Agreement in the Islamic Republic of Iran, GOV/2003/75. Vienna: IAEA.

IAEA. (2004). Implementation of the NPT Safeguards Agreement of the socialist people's Libyan Arab Jamahiriya, GOV/2004/12. Vienna: IAEA.

Kaplow, L., \& Shavell, S. (1994). Accuracy in the determination of law. Journal of Law and Economics, 37(1), 1-15.

Kelly, J. (2004). Dealing with North Korea's nuclear programs. Statement to Senate Foreign Relations Committee, July $15,2004$. Retrieved September 5, 2016, from http://www.state.gov/p/eap/rls/rm/2004/34395.htm

Kerr, P. (2004a). Bush's claim about Iraq's nuclear program. Arms Control Association. Retrieved September 5, 2016, from https://www.armscontrol.org/print/1361

Kerr, P. (2004b). Deconstructed: North Korea's nuclear programs. Arms Control Association. Retrieved September 5, 2016, from https://www.armscontrol.org/act/2004_01-02/Deconstructed

Litwark, R. (2000). Rogue states and U.S. foreign policy: Containment after the Cold War. Baltimore: Johns Hopkins University Press.

Mazarr, M. J. (1995). North Korea and the bomb: A case study in nonproliferation. London: Macmillan.

Mookherjee, D., \& Png, I. P. L. (1992). Monitoring vis-à-vis investigation in enforcement of law. American Economic Review, 82(3), 556-565. 
Morrow, J. D. (1994). Game theory for political scientists. Princeton: Princeton University Press.

Nalebuff, B. (1991). Rational deterrence in an imperfect world. World Politics, 43, 313-335.

Niksch, L. A. (2002). North Korea's nuclear weapons program. Congressional Research Service, Order Code IB91141.

Powell, R. (1990). Nuclear deterrence theory: The search for credibility. Cambridge: Cambridge University Press.

Ritter, S. (1999). Endgame: Solving the Iraq crisis. New York: Simon \& Schuster.

Sigal, L. V. (1998). Disarming strangers: Nuclear diplomacy with North Korea. Princeton: Princeton University Press.

Taft IV, W., \& Buchwald, T. F. (2003). Preemption, Iraq, and international law. American Journal of International Law, 97(3), 557-563.

UNMOVIC. (2003). Unresolved disarmament Issues: Iraq's proscribed weapons programmes. New York: United Nations.

UN Security Council. (1991). Resolution 687, adopted at the 2981st meeting on April 3.

UN Security Council. (1999). Resolution 1284, adopted at the 4084th meeting on December 17.

UN Security Council. (2002). Resolution 1441, adopted at the 4644th meeting on November 8.

White House. (2002a). The National Security Strategy of the United States of America, September.

White House. (2002b). National strategy to combat weapons of mass destruction. December. Retrieved from http://www.whitehouse.gov/news/releases/2002/12/WMDStrategy.pdf

Woodward, B. (2004). Plan of attack. New York: Simon \& Schuster, Inc.

Yoo, J. (2003). International law and the war in Iraq. American Journal of International Law, 97(3), 563-576. 